\title{
Determination of Mineral Abundances in Samples from the Exploratory Studies Facility Using X-Ray Diffraction
}

\author{
Sarah Roberts \\ Brian Viani
}

January 13, 1998

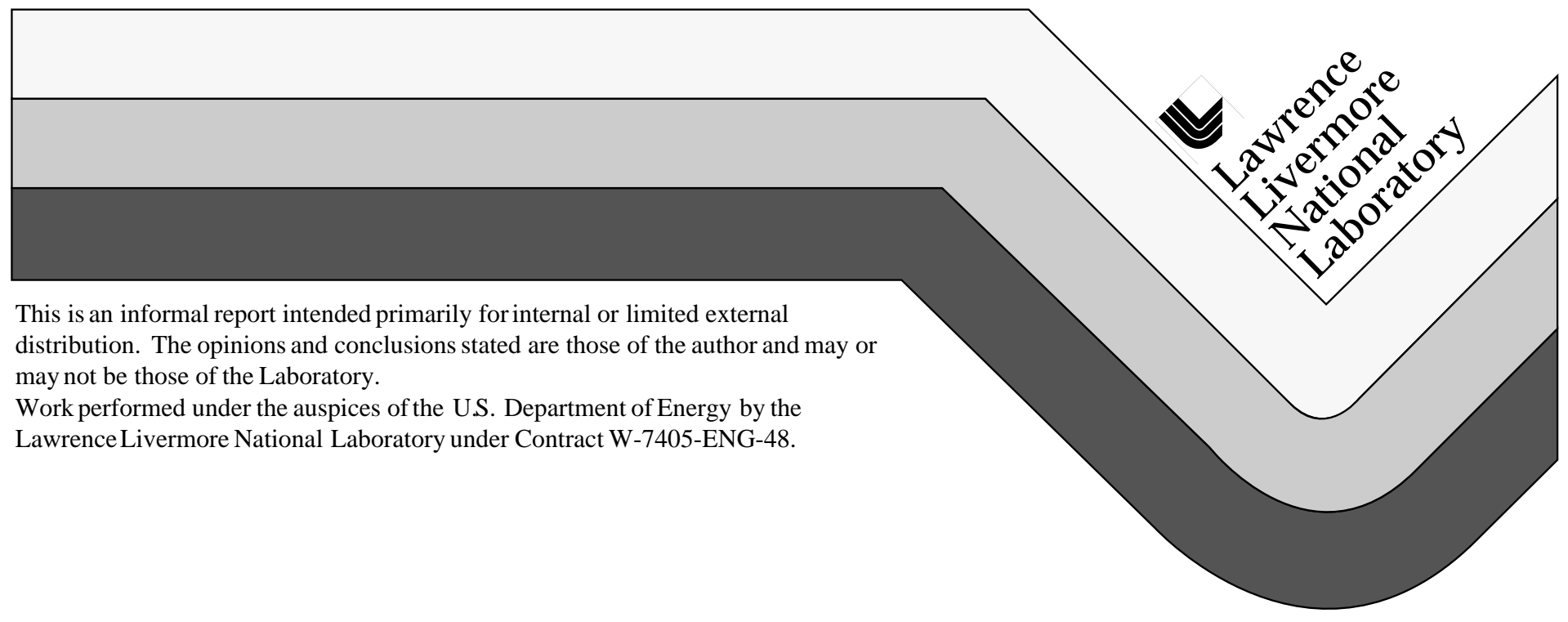




\section{DISCLAIMER}

This document was prepared as an account of work sponsored by an agency of the United States Government. Neither the United States Government nor the University of California nor any of their employees, makes any warranty, express or implied, or assumes any legal liability or responsibility for the accuracy, completeness, or usefulness of any information, apparatus, product, or process disclosed, or represents that its use would not infringe privately owned rights. Reference herein to any specific commercial product, process, or service by trade name, trademark, manufacturer, or otherwise, does not necessarily constitute or imply its endorsement, recommendation, or favoring by the United States Government or the University of California. The views and opinions of authors expressed herein do not necessarily state or reflect those of the United States Government or the University of California, and shall not be used for advertising or product endorsement purposes.

This report has been reproduced directly from the best available copy.

Available to DOE and DOE contractors from the Office of Scientific and Technical Information P.O. Box 62, Oak Ridge, TN 37831

Prices available from (423) 576-8401

Available to the public from the National Technical Information Service

U.S. Department of Commerce 5285 Port Royal Rd. Springfield, VA 22161 


\title{
Determination of Mineral Abundances in Samples from the Exploratory Studies Facility Using X-ray Diffraction
}

Deliverable SPY195M4

January 13, 1998

Sarah Roberts and Brian Viani

\author{
Geosciences and Environmental Technologies Division \\ Lawrence Livermore National Laboratory
}

\section{Introduction}

Tuff samples collected from the Exploratory Studies Facility (ESF) were X-rayed to estimate relative mineral abundances. X-ray analysis was performed on sub-samples of specimens collected from both the Single Heater Test (SHT) and Drift Scale Heater Test (DST) that were used for thermomechanical measurements, as well as samples collected from cores retrieved from boreholes in the Drift Scale Test Area. The abundance of minerals that could affect the behavior of the host rock at repository relevant temperatures is of particular interest. These minerals include cristobalite, which undergoes a phase transition and volume change at elevated temperature $\left(\sim 250{ }^{\circ} \mathrm{C}\right)$, and smectite and clinoptilolite that can dehydrate at elevated temperature with accompanying volume reduction. In addition, the spatial distribution of $\mathrm{SiO}_{2}$ polymorphs and secondary minerals may provide evidence for deducing past fluid pathways. The mineral abundances tabulated here include data reported previously in three milestone reports (Roberts and Viani, 1997a,b; Viani and Roberts, 1996) but re-analyzed (see below), as well as previously unreported data.

Previous X-ray diffraction analyses of samples from the ESF (Roberts and Viani, 1997a; Viani and Roberts, 1996) utilized the matrix flushing method of Chung (1974) and an internal intensity standard (corundum) to quantify the abundances of the phases present. Although the method is adequate for obtaining relative abundances, its accuracy and precision is limited by the inherent differences between the external standards used to compute the reference intensity ratio and the mineral phases in the sample. In a subsequent report (Roberts and Viani, 1997b) mineral abundances were obtained using the Rietveld method of whole X-ray pattern fitting (Snyder and Bish, 1989; Young, 1993). The Rietveld technique has the potential to be both more accurate and more precise for estimating mineral abundances (Snyder and Bish, 1989).

The mineral abundances originally determined using the matrix flushing method (Viani and Roberts, 1996; Roberts and Viani, 1997a) have been re-determined using the Rietveld method using the original X-ray data and are reported in Tables 1 and 2. In addition, mineral abundances determined using the Rietveld method (Roberts and Viani; 1997b) were also re-analyzed using the optimized Rietveld parameters used to re-analyze the earlier data sets (Table 3). Finally, X-ray diffraction data for 
DST drillcore samples not reported in the earlier reports were also analyzed using the Rietveld method (Table 2). The data presented in Tables 1-3 represent our best estimates of mineral abundances for the listed samples. This data supercedes the mineral abundances previously reported in Roberts and Viani (1997a,b) and Viani and Roberts (1996).

In addition to the samples analyzed for abundance, a suite of accompanying fracture and cavity fill minerals was also analyzed to identify the phases present. The results of these analyses are shown in Table 4.

\section{Method}

The Rietveld method is based on fitting a calculated X-ray diffraction (XRD) pattern to the observed pattern over the entire angular range over which data is collected. The calculated pattern is refined by adjusting the quantity of the phases included in the calculation (scale factor), as well as their crystallographic properties. The Rietveld method of quantification avoids the use of external standards. The method requires identification of all the phases in the sample, as the refined abundances are normalized to $100 \%$. In order to assess the overall accuracy of the method, a known quantity of corundum was added to each sample.

Mineral quantification using the Rietveld method involved two steps. First, the phases present in each sample were identified using an XRD pattern processing software program (Jade, version 3.0, Materials Data, Inc., Livermore, CA), which utilizes data from the Joint Committee on Powder Diffraction Standards Powder Diffraction File (JCPDS-PDF). After the mineral phases were identified, the Rietveld method of quantification was employed. A least squares refinement is carried out until the best fit is obtained between the observed powder diffraction pattern and the calculated pattern based on the crystal structures and lattice parameters of phases determined to be present. The Rietveld analyses were performed using a quantitative XRD software program (Siroquant, version 2.0, Sietronics, Australia).

\section{Sample and standard preparation}

All samples were crushed using an hydraulic press to $<1 / 4$-inch, then processed through a flat-plate pulverizer until the entire sample passed a $250-\mu \mathrm{m}$ sieve. A subsample of each was then further ground in a vibratory micro-mill (Fritsch) with a sintered corundum mortar and ball for 60 minutes at $\sim 1 / 3$ full power using an intermittent power cycle. Standard mineral specimens were crushed by hand, if necessary, and then ground in the micro-mill in the same fashion as the tuff samples. Accompanying fracture minerals were hand picked out of the cores and ground as described above. The particle sizes of the milled samples and standards were checked using an optical microscope. Particle sizes determined by this method were approximately $10 \mu \mathrm{m}$ or less. The corundum internal standard (Buehler, 1.0$\mu \mathrm{m} \mathrm{Al}_{2} \mathrm{O}_{3}$ ) was not ground because of its small size. The ground samples were mixed with corundum in a 4:1 ratio, and again placed in the micro-mill for 30 minutes 
using the power cycles described above. Samples were packed into stainless steel side-mount holders having a sample length of $18 \mathrm{~mm}$ and width of $13 \mathrm{~mm}$.

Sub-samples from specimens used for SHT and DST thermomechanical tests (Tables 1 and 3) were ground and homogenized; that is, there was no attempt to sample these on the basis of morphology. In contrast, the samples collected from DST drillcore (Table 2) were sampled on the basis of color variation. Three distinct colors were observed: dark purple and brown zones in the matrix, and gray zones adjacent to lithophysae and fractures. To determine if a mineralogical difference existed between the three matrix types, samples of each of these were selected for X-ray analysis. The sampling protocol consisted of examining each core sample individually and choosing either one or two of the matrix types for analysis.

\section{X-ray diffractometer instrumental parameters}

X-ray scans were collected using a Scintag PAD-V generator equipped with a $\mathrm{Cu} X-$ ray tube operated at $45 \mathrm{kV}$ and $35 \mathrm{~mA}$, and a Sieffert goniometer with a solid-state detector. Diffraction patterns were collected in step scan mode at 2 seconds per $0.02^{\circ}$ 20. Collimation was provided by a $1^{\circ}$ divergence and $2^{\circ}$ scatter slit on the $X$-ray tube and a $0.3-\mathrm{mm}$ scatter and $0.2-\mathrm{mm}$ registration slit on the detector. Samples were scanned from $2-52^{\circ}, 2-72^{\circ}$, or $2-82^{\circ} 2 \theta$.

\section{Calibration correction}

Prior to mineral phase identification and Rietveld analysis, the observed diffraction pattern was corrected for instrumental error based on a calibration curve determined using standard phases. The calibration correction used to correct data for this report was derived by scanning two standards; a fluorophlogopite mica for the low angle peaks (NIST traceable), and a mixture of silicon (NIST traceable), tungsten, and silver metals (SiWAg) for the high angle peaks. Both standards were scanned with the same instrumental parameters listed in the above section, the mica from 2$72^{\circ} 2 \theta$; and the SiWAg from $20-110^{\circ} 2 \theta$. The two scans were merged into one and a calibration curve built on observed versus the NIST and JCPDS-PDF $2 \theta$ angles.

\section{Identification of mineral phases present}

The Jade pattern-processing program was used to identify major and minor mineral phases present in each sample. The Jade program searches located peaks only, and compares them with the strongest lines of a potential phase in the PDF database. The selected peaks are checked visually to confirm realistic phase identification.

\section{Rietveld quantitative analysis parameters}

To calculate (or refine) an XRD pattern, Siroquant uses crystallographic information from its database, and refines these default values to achieve a good fit to the observed data. The program refines the most important parameters first, and then progresses to secondary parameters. This produces an optimum fit and the most 
accurate quantification of the abundances. For this report, all XRD patterns were analyzed using the same refinement parameters. These parameters, obtained after trying a variety of refinement procedures, produced the best estimate for the abundance of the corundum internal standard ( $20 \%$ by weight).

The X-ray analyses from previous reports (Viani and Roberts, 1996; Roberts and Viani, 1997a,b), and new data not previously reported, have been analyzed according to the following procedure. Background is removed from the observed XRD diffraction pattern and a task is produced which specifies which mineral phases are to be included in the model. The calculated XRD pattern is then refined by varying the following parameters in the following order:

- Scale (i.e., abundance of each identified phase)

- Instrument zero

- Peak width factor $(W)$

- Unit cell dimensions $(a, b, c)$ (dependent on phase)

Each set of refinement parameters was refined for 10 cycles with a damping factor of 0.2 to reduce parameter oscillations. Additional refinement cycles were performed if chi-squared (error associated with refinement parameters) for any phase did not indicate a good fit. Refinement was terminated when chi-squared had reached its lowest level for all phases. The output from Siroquant consists of the abundances of the identified phases (including the corundum internal standard) normalized to $100 \%$. For the three data sets tabulated the average value of the corundum abundance varied between 20.6 and $22 \%$. The mineral abundances reported in Tables 1-3 have been re-normalized on a corundum-free basis.

\section{Comparison of most recent analysis of mineral abundances with previous results}

Figures 1 and 2 compare the abundance of quartz and cristobalite determined previously using the matrix flushing method (but normalized to $100 \%$ for comparison to current results) to the mineral abundances calculated using the optimized Rietveld method described above. For quartz and cristobalite, both methods result in similar estimates of their abundance. In contrast, the estimates of abundances of individual feldspar phases differ significantly (not shown), but the estimates of total feldspar abundances are similar for each method. We attribute the discrepancy in feldspar abundances to the difficulty of using the matrix flushing method to estimate abundances for these chemically variable minerals (Vaniman et al., 1996; Roberts and Viani, 1997a).

The greatest difference between the two methods is in the estimate of the abundance of smectite. The Rietveld method consistently returned abundance values near zero for samples in which smectite was identified and for which the matrix flushing method produced values between 1 and 5\%. The smectite abundances estimated using the matrix flushing method are similar to smectite values reported in Vaniman et al. (1996) for Topopah Spring tuff samples. However, we believe that, aside from the discrepancies in the smectite abundances, mineral abundances 
estimated using the Rietveld approach are not only more easily obtained, but are more accurate and precise.

Re-analysis of the DST drillcore data from Roberts and Viani (1997a) resulted in the identification of stellerite in one sample that had not been identified previously. An additional sample containing stellerite was noted in a sample analyzed subsequent to Roberts and Viani's (1997a) report.

\section{Results and Discussion}

Except for one sample containing $12 \%$ zeolite (stellerite), $\mathrm{SiO}_{2}$ polymorphs and feldspars comprise $\geq 95 \%$ by weight of the samples analyzed (Tables 1-3). Small amounts of mica, smectite, clinoptilolite, and stellerite were measured in roughly a quarter of the samples. The total abundance of $\mathrm{SiO}_{2}$ polymorphs and feldspars is quite uniform, averaging between 30.5 and $34.5 \%$, and 65.4 and $67.1 \%$, respectively, for the three data sets. As might be expected, the data for the homogenized samples (thermal test specimens for the SHT and DST; Tables 1 and 3) show less variability than the data for samples collected from the DST drillcore on the basis of color (Table 2). The observed uniformity in total $\mathrm{SiO}_{2}$ polymorphs and total feldspar abundances is consistent with the highly uniform chemical composition of these rocks (Schuraytz et al., 1986; Vaniman et al., 1996).

The uniformity of total $\mathrm{SiO}_{2}$ polymorphs and total feldspar abundances were also noted by Vaniman et al. (1996) for the Topopah Spring. However, the average abundances reported here, differ from the abundances reported by Vaniman et al. (1996) for a relatively densely spaced set of core samples (UE-25 UZ\#16) taken from the upper lithophysal to lower lithophysal units of the Topopah Spring ( 139-329 m). Vaniman et al. report higher abundances of $\mathrm{SiO}_{2}$ polymorphs ( 40 vs. $\left.\sim 33 \%\right)$, lower total feldspar ( $\sim 55$ vs. $\sim 66 \%$ ), and higher secondary minerals ( $\sim 6$ vs. $\sim 1 \%$ ). The relatively large zeolite (stellerite) abundances reported by Vaniman et al. (especially in the lower lithophysal unit) were thought to be relatively unique to the repository horizon intersected by UE-25 UZ\#16. Our identification of stellerite in three samples from the DST area is consistent with the findings of Vaniman et al. (1996), and suggests that stellerite in the Topopah Spring may be more widely distributed than previously thought. Other data for the Topopah Spring reported in Vaniman et al. (though not as densely sampled) are more similar to the data reported here (e.g., UE$25 \mathrm{a} \# 1-\mathrm{SiO}_{2}$ polymorphs $34 \%$, total feldspar $63 \%$; UE- $25 \mathrm{p} \# 1-\mathrm{SiO}_{2}$ polymorphs $34 \%$, total feldspar $64 \%$; USW G-1 - $\mathrm{SiO}_{2}$ polymorphs $33 \%$, total feldspar $63 \%$ ).

The average abundances for the internal corundum standard (Tables 1-3) are consistently larger than $20 \%$, implying that we may not be identifying a phase(s) that comprises 3-9\% of the sample by weight. However, a systematic error arising from a missed phase would tend to overestimate the abundances of all remaining phases, and this alone can not explain the differences between Vaniman et al. (1996) and our data. At least some of the differences between the data reported by Vaniman et al. and that reported here is probably due to differences between quantification by the 
Rietveld method and the matrix flushing method. As mentioned in earlier reports (Viani and Roberts, 1996; Roberts and Viani, 1997a,b) and as discussed by Vaniman et al. (1996), there can be significant errors and difficulties associated with the matrix flushing method, especially for feldspars which display solid-solution behavior, and for samples with many overlapping peaks, such as the samples in question.

\section{$\mathrm{SiO}_{2}$ polymorphs}

An important finding that has not been noted before, is the correlation between matrix color and $\mathrm{SiO}_{2}$ mineralogy, and the negative correlation observed between cristobalite abundance and the sum of quartz plus tridymite (Figures 2 and 3). The negative correlation simply reflects the near uniformity in the abundance of total $\mathrm{SiO}_{2}$ polymorph in these samples. Although the relationship is not quite inverse (the absolute value of the slopes of the best fit lines are less than unity), the negative correlation, and the correlation to matrix color discussed below, suggests that differing degrees of alteration of cristobalite (and possibly tridymite) to the more thermodynamically stable quartz has occurred in a more-or-less closed system.

As shown in Figure 3, the gray matrix zones adjacent to lithophysae and fractures have greater abundances of quartz and tridymite than samples of the purple or brown colored matrix. In almost all cases, gray matrix samples have higher quartz plus tridymite abundances than highly colored samples collected from the same drillcore (Table 2).

Tridymite abundance has been related to vapor phase precipitation on fracture and lithophysae surfaces (Vaniman et al., 1996), hence its greater abundance in the gray zones adjacent to fractures and lithophysal cavities is reasonable. However, tridymite was also identified in the more highly colored matrix zones that are apparently not adjacent to macroscopic fractures or lithophysae. As noted by Vaniman et al. (1996), microscopic fractures may be the source of tridymite in zones not adjacent to readily observable fractures or lithophysae.

These data suggest that alteration of cristobalite to quartz may have been favored in the zones adjacent to fluid pathways (i.e., interconnecting fractures and lithophysae) and may support the hypothesis that liquid water is necessary for the conversion of cristobalite to more stable phases (e.g., Ernst and Calvert, 1969). Whether the increased tridymite abundances in the gray matrix zones reflect vapor phase deposition at the time of devitrification, or subsequent aqueous phase alteration of cristobalite to a more stable phase, cannot be ascertained without supporting textural evidence.

Color differences of the matrix have been explained as differences in the distribution of hematite; more highly colored zones (brown and purple) are characterized by 
small quantities of finely disseminated hematite, gray zones by hematite that is more localized (e.g., as fracture lining minerals), or as zones from which hematite has been depleted. The relationship between hematite distribution and $\mathrm{SiO}_{2}$ mineralogy, if any, cannot be assessed from the data in this report. However, if hematite redistribution in the matrix is a result of post devitrification fluid flow regimes, then perhaps hematite redistribution and alteration of cristobalite to quartz occurred in response to the same flow events.

\section{Fracture minerals}

The cavity and fracture fill samples were hand picked out of the core sections to obtain specific phases for X-ray analysis. The representative phases include lithophysae cavity fill crystals, breccia fill crystals, black lathe-like crystals, and two matrix material samples. Two matrix types were also analyzed qualitatively; a purple matrix sample, and a conglomerate matrix sample exhibiting all three color variations. The results of these analyses are shown in Table 4 . The diffraction patterns yielded relatively pure quartz for the lithophysae cavity fillings from boreholes CHE-1,5,6, and 10, and quartz with minor tridymite in the samples from boreholes CHE-5 and 6. One lithophysae fracture fill sample (CHE-1, 66.6-67.3) yielded quartz with minor feldspars, due to inclusion of some of the surrounding matrix in the sample. Sample CHE-1,122.6-123.2 yielded coexisting calcite and quartz. Breccia fill samples from boreholes CHE-2 and CHE-10 yielded large $(\sim 0.5 \mathrm{~cm}$ square) crystals, determined to be calcite. A relatively large single crystal of hematite was identified in CHE-1. A manganese oxide phase (pyrolusite) was tentatively identified in CHE-10; the mass of material isolated was very small, and the diffraction pattern obtained yielded poor peak intensities. The conglomerate matrix sample was composed of cristobalite, quartz, feldspars, and a minor amount of smectite. The purple matrix sample contained cristobalite as the silica phase, with feldspars and a minor amount of smectite.

\section{Conclusions}

X-ray analysis of samples of Topopah Spring tuff has shown, in agreement with previous work, the uniformity of the total $\mathrm{SiO}_{2}$ polymorph and feldspar abundances in the repository horizon. Within the repository horizon and adjacent zones of the Topopah Spring member, the relative abundance of quartz plus tridymite is positively correlated with gray altered zones adjacent to lithophysae and fractures. The relative abundance of cristobalite relative to quartz plus tridymite could potentially be used to assess the density of paleo fluid pathways. A strong negative correlation between cristobalite and quartz plus tridymite abundances may reflect post-devitrification alteration by aqueous fluids. 


\section{References}

Chung, F.H. 1974. Quantitative interpretation of x-ray diffraction patterns of mixtures. I. Matrix-flushing method for quantitative multicomponent analysis. J. Appl. Cryst. 7: 519-525.

Ernst, W.G., and Calvert, S.E. 1969. An experimental study of the recrystallization of porcelanite and its bearing on the origin of some bedded cherts: Amer. Jour. Sci., 267A:114-133.

Roberts, S.K., and Viani, B.E., 1997a. Mineral Abundances for Samples from Six Chemistry (Seamist) Boreholes in the Drift Scale Area (DST) of the ESF, Yucca Mountain Project Milestone SP9510M4, Lawrence Livermore National Laboratory, February 28, 1997.

Roberts, S.K., and Viani, B.E. 1997b. Mineral Abundances For Samples from Instrumentation Boreholes in the Access Drift Scale Test Area (DST) Of The ESF Yucca Mountain Project Milestone Report SP9511M4, Lawrence Livermore National Laboratory, May 30, 1997

Schuraytz, B.C, Vogel, T.Z, and Younker, L.W. 1986. Geochemical Gradients in the Topopah Spring Member of the Paintbrush Tuff: Evidence for Eruption Across a Magnetic Interface. Lawrence Livermore National Laboratory, Livermore, CA. UCRL-53698.

Snyder, R.L., and Bish, D.L. 1989. Quantitative analysis. In. Bish, D.L., and Post, J.E. (eds.) Modern Powder Diffraction. Pp. 101-144. Reviews in Mineralogy, Mineralogical Society of America, Washington DC.

Vaniman, D.T., Bish, D.L., Chipera, S.J., Carlos, B.A., and Guthrie, Jr., G.D. 1996. Summary and Synthesis Report on Mineralogy and Petrology Studies for the Yucca Mountain Site Characterization Project. Volume I. Chemistry and Mineralogy of the Transport Environment at Yucca Mountain M0L.19961230.0037. Yucca Mountain Project Milestone 3665. Los Alamos National Laboratory, Los Alamos, NM.

Viani, B.E., and Roberts, S.K. 1996. Determination of Mineral Abundances in Core Samples From the Exploratory Studies Facility Using Xray Diffraction. Analysis report supporting Yucca Mountain Project TDIF\# 305632; Mineral Abundances for Ten Samples From the Thermal Area of the ESF.

Young, R.A., 1993. Introduction to the Rietveld method. In Young, R.A. (ed). The Rietveld Method, p.1-38. IUCr Monographs on Crystallography 5, Oxford University Press, New York. 
Table 1. Normalized mineral abundances ${ }^{(1)}$ (weight-\%) for samples from the Exploratory Studies Facility: Thermal test specimens from the SHT

(Re-analyzed data originally reported in Viani and Roberts (1996))

\begin{tabular}{|c|c|c|c|c|c|c|c|}
\hline Sample \# & quartz & cristobalite tridymite & albite & sanidine & $\begin{array}{c}\text { clinoptiloli } \\
\text { te }\end{array}$ & smectite & muscovite \\
\hline BJ-1-1.0-B & 10 & 22 & 26 & 39 & & $\operatorname{tr}^{(2)}$ & 3 \\
\hline BJ-1-10.0-B & 9 & 22 & 25 & 42 & & $\operatorname{tr}$ & \\
\hline BJ-1-18.0-B & 8 & 22 & 28 & 41 & & $\operatorname{tr}$ & \\
\hline BJ-1-18.0-B & 6 & 22 & 27 & 42 & & 1 & \\
\hline MPBX-2-8.6-D & 6 & 25 & 23 & 41 & & 1 & 3 \\
\hline MPBX-3-12.5-B & 9 & 20 & 24 & 42 & 3 & $\operatorname{tr}$ & \\
\hline MPBX-3-12.5-B & 13 & 21 & 19 & 42 & 4 & $\operatorname{tr}$ & \\
\hline MPBX-4-5.0-B & 2 & 28 & 28 & 41 & & $\operatorname{tr}$ & \\
\hline $\mathrm{H} 1-0.6-\mathrm{C}$ & 8 & 20 & 27 & 42 & 1 & $\operatorname{tr}$ & \\
\hline $\mathrm{H} 1-11.3-\mathrm{C}$ & 8 & 24 & 25 & 42 & & $\operatorname{tr}$ & \\
\hline H1-11.6-C & 8 & 22 & 29 & 39 & & $\operatorname{tr}$ & \\
\hline H1-22.2-B & 8 & 23 & 22 & 46 & & $\operatorname{tr}$ & \\
\hline H1-22.2-B & 7 & 24 & 25 & 42 & & 1 & \\
\hline
\end{tabular}

(1) Normalized on corundum free basis (totals may not sum to 100 due to round-off error). Average corundum abundance 21.3 \pm 0.5 . Average normalized abundances: total $\mathrm{SiO}_{2}$ polymorphs $-30.5 \pm 1.7$; total feldspars $-66.8 \pm 2.4$; albite $-25.2 \pm 2.8$; sanidine - 41.6 \pm 1.7 .

(2) $\mathrm{tr}$ - the phase was identified in the XRD pattern, but Siroquant Rietveld analysis refined the abundance to zero. 
Table 2. Normalized mineral abundances ${ }^{(1)}$ (weight-\%) for samples from the Exploratory Studies Facility: Samples collected fron DST drill core

(Re-analyzed data originally reported in Roberts and Viani (1997a), and new data not previously reported).

\begin{tabular}{|c|c|c|c|c|c|c|c|c|}
\hline $\begin{array}{l}\text { DST Borehole \#, depth } \\
\text { interval }\end{array}$ & quartz & cristobalite & tridymite & albite & sanidine & zeolite $^{(2)}$ & smectite & sample color \\
\hline CHE-1, 32.0-32.8 & 2 & 29 & & 27 & 43 & & & purple \\
\hline CHE-1, 53.4-54.2 & 11 & 23 & & 27 & 40 & & & brown \\
\hline CHE-1, 53.4-54.2 & 17 & 13 & 7 & 28 & 36 & & & gray \\
\hline CHE-1, 66.6-67.3 & 10 & 21 & & 28 & 42 & & & gray \\
\hline CHE-1, 76.7-77.6 & 33 & 3 & 7 & 28 & 29 & & & gray \\
\hline CHE-1, 76.7-77.6 & 8 & 24 & & 24 & 44 & & & brown \\
\hline CHE-1, 85.7-86.6 & 16 & 5 & 7 & 33 & 38 & & & gray \\
\hline CHE-1, 85.7-86.6 & 6 & 23 & & 33 & 38 & & & brown \\
\hline CHE-1, 122.6-123.2 & 5 & 26 & & 31 & 38 & & & brown \\
\hline CHE-2, 18.4-19.1 & 8 & 22 & & 24 & 45 & & $\operatorname{tr}^{(3)}$ & brown \\
\hline CHE-2, 50.3-51.0 & 16 & 17 & & 28 & 38 & & $\operatorname{tr}$ & brown \\
\hline CHE-2, 65.0-65.7 & 10 & 17 & 10 & 25 & 38 & & & gray \\
\hline CHE-2, 76.7-77.4 & 4 & 25 & & 29 & 43 & & $\operatorname{tr}$ & purple \\
\hline CHE-2, 89.0-89.7 & 3 & 30 & & 27 & 40 & & & purple \\
\hline CHE-2, 97.0-97.7 & 4 & 24 & 10 & 30 & 33 & & & dark purple \\
\hline CHE-2, 114.0-114.7 & 20 & 13 & & 29 & 37 & & & brown \\
\hline CHE-2, 114.0-114.7 & 23 & 14 & & 29 & 34 & & & gray \\
\hline CHE-2, 128.9-129.6 & 17 & 8 & 13 & 24 & 39 & & & gray \\
\hline CHE-2, 128.9-129.6 & 9 & 17 & 2 & 34 & 38 & & $\operatorname{tr}$ & brown \\
\hline CHE-5, 5.2-6.0 & 14 & 19 & & 31 & 37 & & & brown \\
\hline CHE-5, 5.2-6.0 & 19 & 8 & & 33 & 40 & & & gray \\
\hline
\end{tabular}


Table 2. Normalized mineral abundances ${ }^{(1)}$ (weight-\%) for samples from the Exploratory Studies Facility: Samples collected fron DST drill core

(Re-analyzed data originally reported in Roberts and Viani (1997a), and new data not previously reported).

\begin{tabular}{|c|c|c|c|c|c|c|c|c|}
\hline $\begin{array}{l}\text { DST Borehole \#, depth } \\
\text { interval }\end{array}$ & quartz & cristobalite & tridymite & albite & sanidine & zeolite $^{(2)}$ & smectite & sample color \\
\hline CHE-5, 50.0-50.7 & 15 & 6 & 10 & 30 & 40 & & & gray \\
\hline CHE-5, 50.0-50.7 & 6 & 26 & & 26 & 42 & & $\operatorname{tr}$ & brown \\
\hline CHE-5, 74.2-74.9 & 8 & 24 & & 25 & 43 & & & brown \\
\hline CHE-5, 74.2-74.9 & 12 & 12 & 14 & 25 & 38 & & & gray \\
\hline CHE-5, 74.2-74.9 & 11 & 11 & 12 & 26 & 39 & & & gray \\
\hline CHE-5, 74.2-74.9 & 4 & 23 & 8 & 31 & 35 & & & dark \\
\hline CHE-5, 82.8-83.5 & 17 & 13 & 4 & 30 & 36 & & & matrix \\
\hline CHE-5, 99.0-99.6 & 13 & 11 & & 25 & 45 & 5 (st) & & gray \\
\hline CHE-5, 99.0-99.6 & 20 & 10 & 5 & 29 & 36 & & & purple \\
\hline CHE-6, 29.0-29.7 & 7 & 23 & 4 & 28 & 37 & & & brown \\
\hline CHE-6, 29.0-29.7 & 14 & 9 & 12 & 27 & 37 & & & gray \\
\hline CHE-6, 63.9-64.6 & 5 & 23 & 7 & 32 & 34 & & & matrix \\
\hline CHE-6, 74.8-75.5 & 5 & 27 & & 28 & 40 & & & purple \\
\hline CHE-6, 74.8-75.5 & 15 & 19 & & 27 & 39 & & & brown \\
\hline CHE-6, 74.8-75.5 & 8 & 16 & 9 & 29 & 38 & & & gray \\
\hline CHE-6, 74.8-75.5 & 4 & 18 & 3 & 47 & 28 & & & purple \\
\hline CHE-6, 74.8-75.5 & 7 & 11 & 14 & 26 & 41 & & & gray \\
\hline CHE-6, 91.3-92.0 & 7 & 22 & 5 & 30 & 35 & & & brown \\
\hline CHE-6, 99.7-100.4 & 5 & 25 & 5 & 28 & 37 & & & brown \\
\hline CHE-6, 99.7-100.4 & 5 & 25 & 5 & 28 & 37 & & & brown \\
\hline CHE-6, 99.7-100.4 & 18 & 19 & & 25 & 38 & & & gray \\
\hline CHE-6, 105.0-105.5 & 7 & 26 & & 28 & 39 & & & brown \\
\hline
\end{tabular}


Table 2. Normalized mineral abundances ${ }^{(1)}$ (weight-\%) for samples from the Exploratory Studies Facility: Samples collected fron DST drill core

(Re-analyzed data originally reported in Roberts and Viani (1997a), and new data not previously reported).

\begin{tabular}{|c|c|c|c|c|c|c|c|c|}
\hline $\begin{array}{l}\text { DST Borehole \#, depth } \\
\text { interval }\end{array}$ & quartz & cristobalite & tridymite & albite & sanidine & $z_{\text {zeolite }}^{(2)}$ & smectite & sample color \\
\hline CHE-6, 105.0-105.5 & 10 & 6 & 16 & 35 & 33 & & & gray \\
\hline CHE-6, 118.6-119.3 & 7 & 25 & & 30 & 37 & & & brown \\
\hline CHE-6, 118.6-119.3 & 12 & 9 & 17 & 31 & 31 & & & gray \\
\hline CHE-7, 80.0-80.7 & 2 & 28 & 5 & 26 & 39 & & & purple \\
\hline CHE-7, 95.6-96.3 & 24 & 11 & 10 & 23 & 32 & & & gray \\
\hline CHE-7, 95.6-96.3 & 3 & 24 & 7 & 32 & 33 & & & dark \\
\hline CHE-7, 101.0-101.7 & 3 & 25 & 8 & 30 & 34 & & & purple \\
\hline CHE-7, 101.0-101.7 & 16 & 11 & 14 & 21 & 35 & $4(\mathrm{cl})$ & $\operatorname{tr}$ & gray \\
\hline CHE-10, 27.3-28.0 & 16 & 10 & & 28 & 45 & & & light brown \\
\hline CHE-10, 27.3-28.0 & 10 & 20 & 3 & 22 & 45 & & & brown \\
\hline CHE-10, 75.6-76.3 & 7 & 25 & & 28 & 40 & & & brown \\
\hline CHE-10, 75.6-76.3 & 10 & 7 & 16 & 32 & 35 & & & gray \\
\hline CHE-10, 75.6-76.3 & 8 & 19 & 6 & 30 & 38 & & & matrix \\
\hline CHE-10, 80.7-81.4 & 5 & 12 & 3 & 26 & 43 & $12(\mathrm{st})$ & $\operatorname{tr}$ & dark \\
\hline CHE-10, 85.0-85.7 & 17 & 6 & 12 & 30 & 35 & & & gray \\
\hline CHE-10, 85.0-85.7 & 25 & 9 & 2 & 31 & 33 & & & dark \\
\hline CHE-10, 100.1-101.0 & 21 & 6 & 10 & 29 & 35 & & & gray \\
\hline CHE-10, 100.1-101.0 & 24 & 6 & 4 & 34 & 32 & & & dark \\
\hline
\end{tabular}

(1) Normalized on corundum free basis (totals may not sum to 100 due to round-off error). Average corundum abundance 20.6 \pm 1.7.Average normalized abundances: total $\mathrm{SiO}_{2}$ polymorphs $-32.7 \pm 4.2$; total feldspars $-67.1 \pm 4.1$; albite $-27.9 \pm 2.9$; sanidine - 39.2 \pm 4.1

(2) $(\mathrm{cl})=$ clinoptilolite; $(\mathrm{st})=$ stellerite

(3) $\mathrm{tr}$ - the phase was identified in the XRD pattern, but Siroquant Rietveld analysis refined the abundance to zero. 
Table 3. Normalized mineral abundances ${ }^{(1)}$ (weight-\%) for samples from the Exploratory Studies Facility: Thermal test specimens from DST

(Re-analyzed data originally reported in Roberts and Viani, 1997b).

\begin{tabular}{|c|c|c|c|c|c|c|}
\hline Sample \# & quartz & cristobalite & tridymite & albite & sanidine & zeolite $^{(2)}$ \\
\hline SDM-MPBX1-1.0-1.2-D & 11 & 23 & & 23 & 43 & \\
\hline SDM-MPBX1-21.0-21.2-D & 7 & 25 & 4 & 16 & 47 & \\
\hline SDM-MPBX1-21.0-21.2-D dup & 8 & 24 & 6 & 18 & 45 & \\
\hline SDM-MPBX1-31.9-32.1-D & 3 & 31 & & 21 & 45 & \\
\hline SDM-MPBX1-40.4-40.6-D & 17 & 17 & 8 & 17 & 41 & \\
\hline SDM-MPBX1-62.0-D & 9 & 25 & & 22 & 44 & \\
\hline SDM-MPBX1-80.7-80.9-D & 10 & 24 & & 20 & 46 & \\
\hline SDM-MPBX2-29.0-29.2-D & 3 & 28 & & 23 & 45 & \\
\hline SDM-MPBX2-29.0-29.2-D dup & 3 & 29 & & 27 & 42 & \\
\hline SDM-MPBX2-48.6-D & 15 & 19 & & 21 & 45 & \\
\hline SDM-MPBX2-72.0-D & 5 & 29 & & 22 & 44 & \\
\hline SDM-MPBX2-85.0-D & 6 & 27 & & 24 & 43 & \\
\hline SDM-MPBХ3-17.5-17.7-D & 7 & 26 & & 24 & 43 & \\
\hline SDM-MPBХ3-38.5-38.7-D & 4 & 30 & & 21 & 45 & \\
\hline SDM-MPBХ3-85.6-D & 9 & 23 & & 18 & 47 & $3(\mathrm{st})$ \\
\hline AOD-HDFR\#1-9.0-D & 12 & 21 & & 20 & 46 & $1(\mathrm{cl})$ \\
\hline AOD-HDFR\#1-9.0-D dup & 13 & 21 & & 22 & 43 & $\operatorname{tr}^{(3)}(\mathrm{cl})$ \\
\hline AOD-HDFR\#1-48.5-D & 9 & 24 & & 21 & 46 & \\
\hline AOD-HDFR\#1-68.6-D & 11 & 24 & & 21 & 44 & \\
\hline AOD-HDFR\#1-98.0-D & 36 & 3 & & 23 & 39 & \\
\hline
\end{tabular}

(1) Normalized on corundum free basis (totals may not sum to 100 due to round-off error). Average corundum abundance 22.0 \pm 0.8.Average normalized abundances: total $\mathrm{SiO}_{2}$ polymorphs $-34.5 \pm 2.8$; total feldspars $-65.4 \pm 2.8$; albite $-21.4 \pm 3.1$; sanidine - 44.1 \pm 1.7

${ }^{(2)}(\mathrm{cl})=$ clinoptilolite; $(\mathrm{st})=$ stellerite

(3) $\operatorname{tr}$ - the phase was identified in the XRD pattern, but Siroquant Rietveld analysis refined the abundance to zero. 
Table 4. Composition of cavity and fracture fill samples from the DST drill core samples.

\begin{tabular}{|c|c|c|}
\hline Borehole \#, depth int. & Sample type & Composition \\
\hline CHE-1, 53.4-54.2 & Lithophysae cavity filling & quartz \\
\hline CHE-1, 66.6-67.3 & Large lithophysae filling & quartz, minor feldspars ${ }^{(1)}$ \\
\hline CHE-1, 108.2-109.0 & Single black crystal & hematite \\
\hline CHE-1, 108.2-109.0 & Conglomerate matrix & $\begin{array}{l}\text { cristobalite, quartz, } \\
\text { feldspars }{ }^{(1)} \text {, trace of } \\
\text { smectite }\end{array}$ \\
\hline CHE-1,122.6-123.2 & $\begin{array}{l}\text { Coarse grained cavity } \\
\text { filling }\end{array}$ & calcite + quartz \\
\hline CHE-2, 50.3-51.0 & Breccia fracture fill & calcite \\
\hline CHE-2, 89.0-89.7 & Fracture fill crystals & calcite \\
\hline CHE-5, 99.0-99.6 & Fracture fill crystals & quartz, minor tridymite \\
\hline CHE-6, 63.9-64.6 & Fracture fill crystals & quartz, minor tridymite \\
\hline CHE-7, 80.0-80.7 & Purple matrix & $\begin{array}{l}\text { cristobalite, feldspars }^{(1)} \\
\text { trace of smectite }\end{array}$ \\
\hline CHE-10, 27.3-28.0 & Black crystals & manganese oxide \\
\hline CHE-10, 27.3-28.0 & Fracture fill crystals & quartz \\
\hline CHE-10, 85.0-85.7 & $\begin{array}{l}\text { Shallow rim around } \\
\text { lithophysae }\end{array}$ & $\begin{array}{l}\text { quartz, cristobalite, } \\
\text { feldspars }{ }^{(1)} \text {, trace of } \\
\text { smectite }\end{array}$ \\
\hline CHE-10, 124.0-124.7 & Large white vug crystal & calcite \\
\hline
\end{tabular}

(1) primarily albite and sanidine of varying composition 

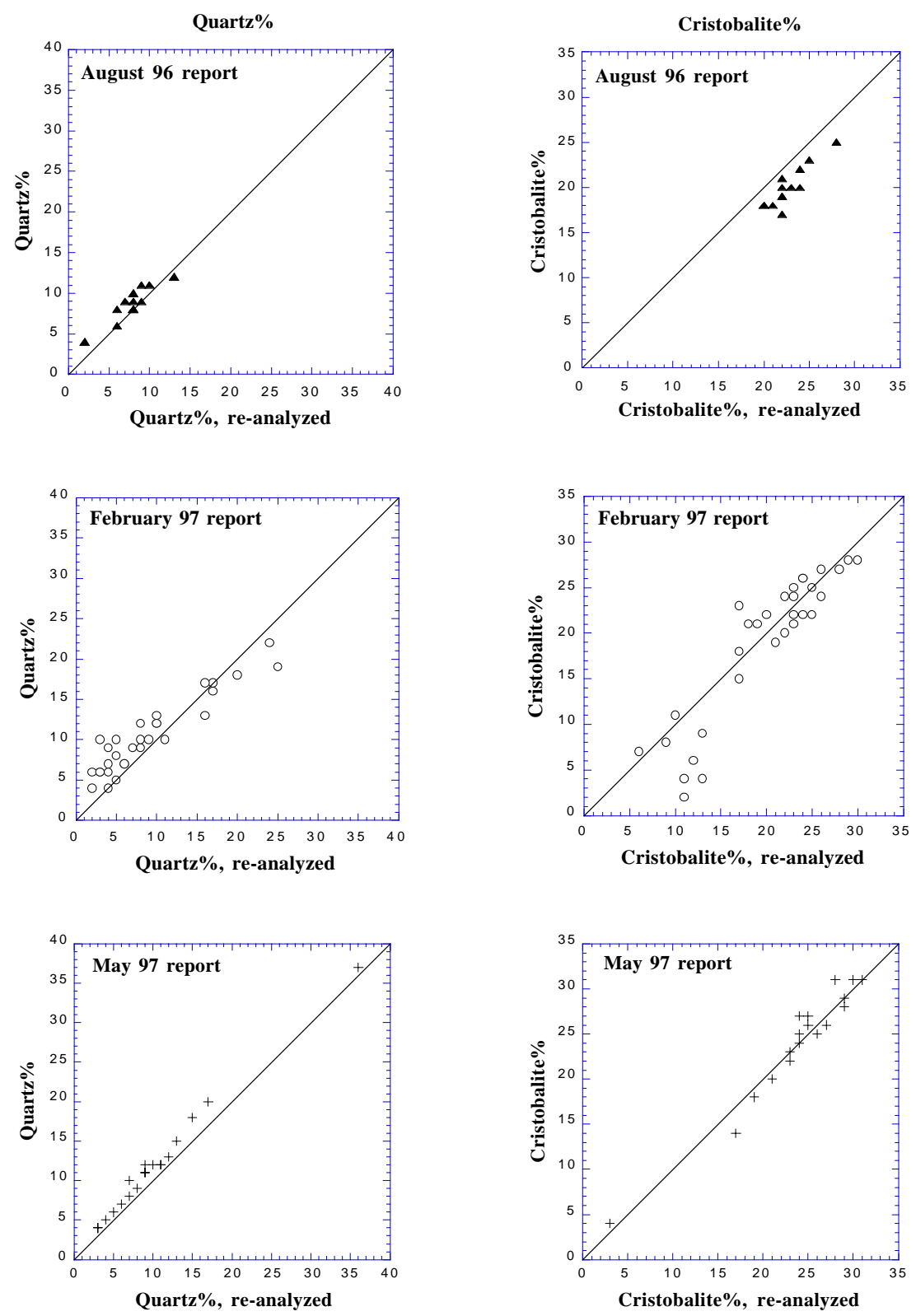

Figure 1. Comparison of normalized abundances of quartz and cristobalite determined using the matrix flushing method (August 96 and February 97 reports; Viani and Roberts, 1996; Roberts and Viani, 1997a) with normalized abundances reanalyzed using the Rietveld method (top and middle graphs). Lower graphs ( May 97 report; Roberts and Viani, 1997b) compare normalized abundances of quartz and 
cristobalite determined using initial and optimized Rietveld method parameters. Solid line represents 1:1 correspondence. 

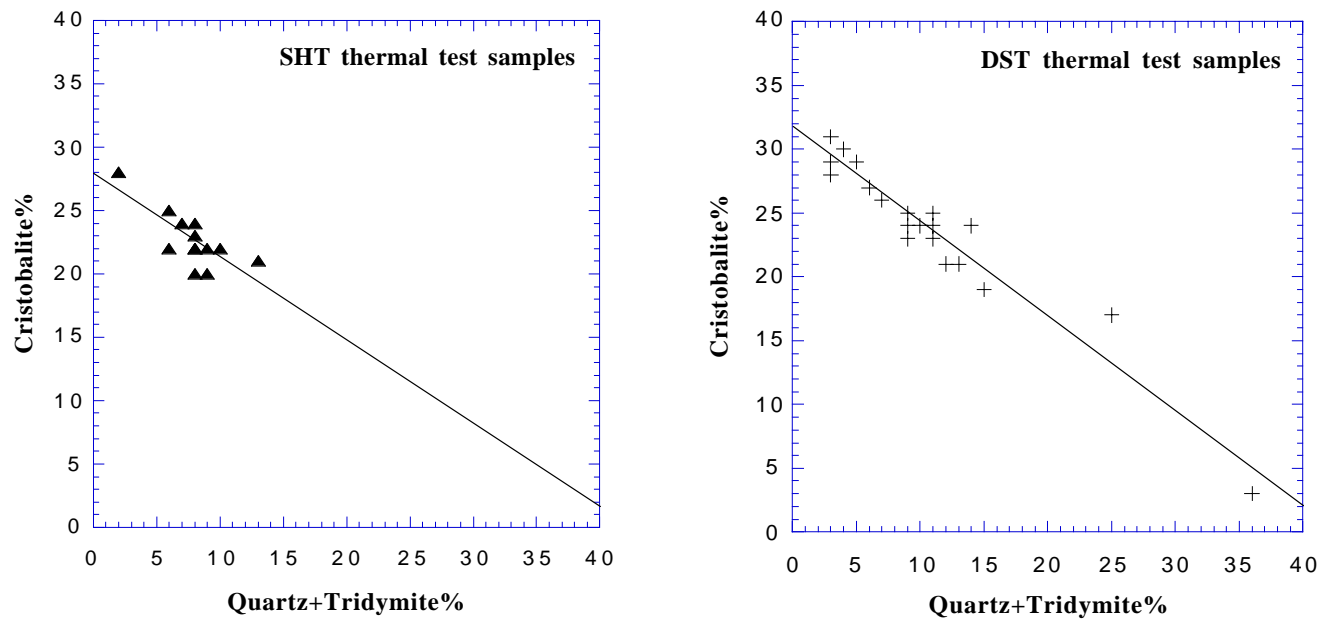

Figure 2. Variation in cristobalite abundance vs. quartz plus tridymite abundance for SHT and DST thermal test samples. Solid line is the best fit regression to the data. 


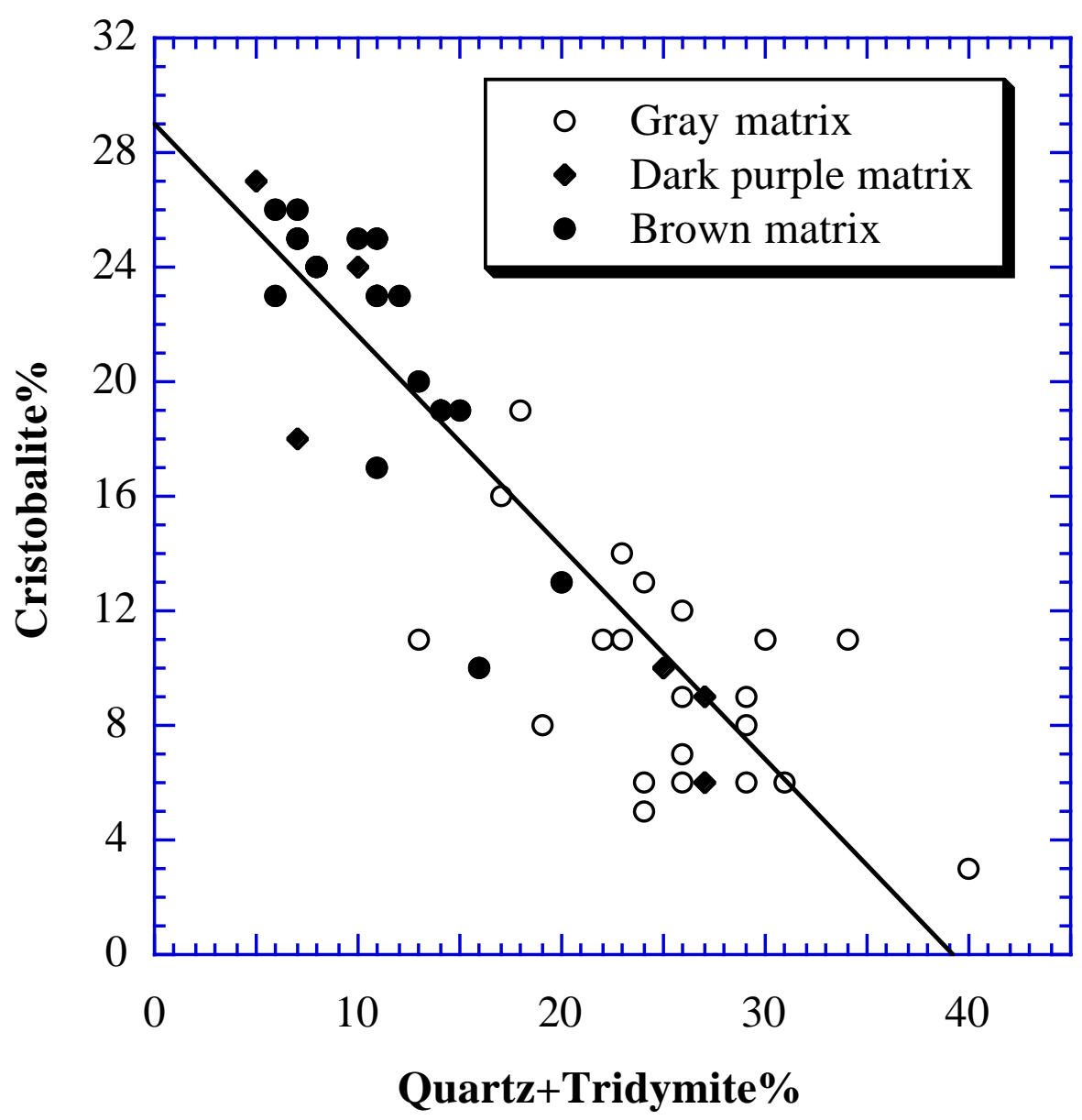

Figure 3. Variation in cristobalite abundance vs. quartz plus tridymite abundance for DST core samples of different matrix color collected from the same core. Solid line is the best fit regression to the data. 